\title{
The inflammatory response to colloids and crystalloids used for pump priming during cardiopulmonary bypass
}

\author{
E. Tamayo ${ }^{1}$, F. J. Álvarez ${ }^{2}$, O. Alonso ${ }^{1}$, J. Castrodeza ${ }^{3}$, R. Bustamante ${ }^{4}$, J. I. Gómez-Herreras ${ }^{5}$, S. Florez ${ }^{6}$, and \\ R. RODRÍGUEZ ${ }^{1}$ \\ ${ }^{1}$ Department of Anaesthesiology and Reanimation, Valladolid University Hospital, Valladolid, Spain, ${ }^{2}$ Department of Pharmacology and \\ Therapeutics, Faculty of Medicine, ${ }^{3}$ Department of Medicine and Public Health, Faculty of Medicine, ${ }^{4}$ Department of Clinical Analysis, \\ University of Valladolid, Valladolid, Spain, ${ }^{5}$ Department of Anaesthesiology and Reanimation, Rio Hortega Hospital, Valladolid, Spain and \\ ${ }^{6}$ Department of Surgery, Faculty of Medicine, University of Valladolid, Valladolid, Spain
}

Background: Systemic inflammatory response frequently occurs after coronary artery bypass surgery and is strongly correlated with the risk of postoperative morbidity and mortality. This study tests the hypothesis that the priming of the extracorporeal circuit with colloid solutions results in less inflammation in patients undergoing cardiac surgery than priming with crystalloid solutions.

Methods: A prospective, randomized study was designed. Forty-four patients undergoing elective coronary artery bypass grafting were randomly allocated to one of two groups: 22 patients primed with Ringer's lactate (RL) solution and 22 patients primed with gelatin-containing solution during the surgery. Plasma levels of interleukin (IL)-6, IL-8, tumor necrosis factor (TNF)- $\alpha$, C-reactive protein (CRP) and, complement 4 were measured during the surgical intervention and over the following 48 postoperative hours. Cytokine levels were measured by enzyme-linked assays from plasma samples obtained at specific time points pre- and post-operatively.

Results: In both groups the serum levels of the pro-inflammatory cytokines (IL-6, IL-8, TNF- $\alpha$ ), CRP, complement 4, and leukocytes increased significantly over the baseline, although no significant differences were observed between the two groups. The operation time, blood loss, need for inotropic support, extubation time, and length of intensive care unit stay did not differ significantly between the two groups.

Conclusion: Priming with gelatin vs. RL produces no significant differences in the inflammatory response in patients undergoing coronary artery bypass grafting with cardiopulmonary bypass.

Accepted for publication 24 June 2008

(C) 2008 The Authors

Journal compilation (C) 2008 The Acta Anaesthesiologica Scandinavica Foundation
C ARDIOPULMONARY bypass (CPB) has been associated, during surgery and in the early postoperative stage, with a large variety of clinical symptoms, including haemodynamic instability (hypotension, vasodilatation), fever, bleeding disorders, and organ dysfunction in severe cases. ${ }^{1}$ It has been suggested that these effects are symptoms of a systemic inflammatory response syndrome (SIRS) resulting from extensive cellular activation, likely caused both by the contact of blood with the foreign material of the extracorporeal circuit and by trauma induced by surgery. This response is mediated by the release of proinflammatory cytokines, especially interleukin (IL)-6, IL-8, and tumor necrosis factor- $\alpha$ (TNF$\alpha){ }^{2-3}$ Because the extent of SIRS is strongly correlated with the risk of postoperative morbidity, efforts to reduce SIRS activation are of potential clinical importance.
Prevention of the inflammatory response due to CPB has been attempted using different perfusion techniques (oxygenator, cardioplegia, biocompatibility of CPB setups) and pharmacological agents (corticosteroids, aprotinin). The composition of the solution used to prime the extracorporeal circuit causes a modulation of the neutrophil complement activation and repercussions in the inflammatory response as well as a modulation in blood levels of inflammatory mediators (cytokines). ${ }^{4-6} \mathrm{~A}$ recent study evaluated the effect of priming the extracorporeal circuit with crytalloid alone, crystalloid plus albumin, or crystalloid plus the plasma expanding polygelatin on complement activation, and the results indicated that the addition of polygelatin to the priming solution reduces complement activation. ${ }^{5}$ Cavarocchi et al. ${ }^{7}$ reported significantly less complement activation with a prime containing $12.55 \mathrm{vol} / 5 \%$ albumin. Other reports suggest that 
priming of extracorporeal circulation with crystalloid (Hartman solutions) may cause an increase in plasma water content ${ }^{8}$ and marked activation of the neutrophil as compared with albumin. ${ }^{4}$

Together this suggests that the use of crystalloid solutions in the priming of the $\mathrm{CPB}$ appears to contribute to greater activation of both neutrophil and complement. Here we test the hypothesis that priming the volume of the extracorporeal circuit with colloid rather than crystalloid solutions results in reduced inflammation [lower cytokine, complement, C-reactive protein (CRP), and leukocyte levels in the blood], thus reducing patient morbidity.

We compared the effects of gelatin priming vs. Ringer's lactate (RL) priming on cytokine release and during the inflammatory state following coronary artery bypass surgery with $\mathrm{CPB}$. We also examined the relationships between cytokines, $\mathrm{CRP}$, and complement levels with postoperative variables at specific time points (respiratory insufficiency, $\mathrm{PaO}_{2} / \mathrm{FIO}_{2}$ ratio, etc.).

\section{Materials and methods}

\section{Study protocol}

Patients scheduled to undergo elective coronary artery bypass graft surgery at our centre were evaluated for possible inclusion in the study. $\mathrm{Pa}-$ tients with renal or hepatic impairment, congestive heart failure, severely impaired left ventricular function (ejection fraction $<40 \%$ ), active inflammatory/immunomodulatory diseases, a history of myocardial infarction $<6$ months previously, and those who had pre-operative use of steroids were excluded. Patients undergoing urgent surgery or repeated surgical interventions were also excluded. Cardiac medications including $\beta$-adrenergic blocking agents, calcium-channel blocking agents, and nitrates were continued until the surgery.

A computerized table of aleatory numbers was used to randomize allocation. Forty-four subjects who fulfilled the inclusion criteria were randomly allocated to one of two groups during CPB: the RL (RL; B. Braun, Melsungen, Germany) prime (RL group, 22 patients) or the gelatin (Gelofusine, B. Braun, Melsungen, Germany) containing prime (GEL group, 22 patients). Except for the perfusionists, the clinical team was blinded to the randomization.

The study protocol was approved by the ethics committee of the 'Clinico' Hospital of Valladolid. Written informed consent was obtained from each patient.
Operative procedure and postoperative care

All patients underwent coronary bypass surgery with $\mathrm{CPB}$ using standard procedures. All patients were premedicated during the night with oral flunitracepam $2 \mathrm{mg}$, and $5 \mathrm{mg}$ of morphine was injected on the morning of the intervention. Arterial pressure, pulse pressure, and EKG were monitored in the operating theatre. A 20-G catheter was then inserted into the radial artery and the internal jugular vein. Anaesthesia was induced in all patients $[0.1 \mathrm{mg} / \mathrm{kg}$ intravenous (i.v.) midazolam, 5-10 $\mu \mathrm{g} / \mathrm{kg}$ i.v. fentanyl, followed by $2-5 \mathrm{mg} / \mathrm{kg}$ i.v. thiopental] and tracheal intubation was facilitated with $1 \mathrm{mg} / \mathrm{kg}$ i.v. rocuronium. After tracheal intubation, the lungs were ventilated to normocapnia using an oxygenair mixture (intake oxygen fraction 0.5). Mechanical ventilation was carried out using an anaesthesia machine, model Datex-Ohmeda S/5 Aespire 3000 (Datex-Ohmeda Ltd., Madson, WI) with controlled ventilation. Anaesthesia was maintained using sevorane $0.5-1.5 \%$, fentanyl $3 \mu \mathrm{g} / \mathrm{kg} / \mathrm{h}$, and rocuronium $0.3 \mathrm{mg} / \mathrm{kg} / \mathrm{h}$. The inspired sevoflurane concentration was varied to maintain the mean arterial pressure (MAP) within $20 \%$ of the preinduction baseline values.

The extracorporeal circulation system consisted of a soft-shell venous reservoir, roller pump, and membrane oxygenator (D903 AVANT with integrated biocompatible circuit covered by phosphorylchlorine inert surface; DIDECO, Mirandola, Italy). In all cases, the extracorporeal circuit was primed with $1750 \mathrm{ml}$. The crystalloid prime solution contained lactated Ringer's solution $1500 \mathrm{ml}, 20 \%$ mannitol $100 \mathrm{ml}$, aprotinin $100 \mathrm{ml}, 8.4 \%$ sodium bicarbonate $50 \mathrm{ml}$, and heparin $5000 \mathrm{IU}$. The colloid prime solution contained gelatin $1000 \mathrm{ml}$, lactated Ringer's solution $500 \mathrm{ml}, 20 \%$ mannitol $100 \mathrm{ml}$, aprotinin $100 \mathrm{ml}, 8.4 \%$ sodium bicarbonate $50 \mathrm{ml}$, and heparin $5000 \mathrm{IU}$.

The heart was exposed through a median sternotomy. To perform sub-total CPB, a standard cannulation was performed with the cannule placed in the ascending aorta and the right atrium. After systemic heparinization (300 IE/ kg), CPB commenced under the condition that the activated clotting time was more than $400 \mathrm{~s}$. The left ventricle was vented via the aortic root. Blood from the pericardial cavity was collected in a cardiotomy reservoir and returned to the patient. The haematocrit value was maintained between $20 \%$ and $25 \%$, and pump flows were kept between 2.0 and $2.51 / \mathrm{min} / \mathrm{m}^{2}$ to maintain MAP between 50 and $70 \mathrm{mmHg}$. If arterial pressure declined below $50 \mathrm{mmHg}$, flow rate increased, and vasoactive drugs were given. All 
Table 1

\begin{tabular}{|c|c|c|c|c|}
\hline Variable & Total $n=44$ & $\mathrm{RL} n=22$ & GEL $n=22$ & $P$-value \\
\hline Age, years & $67 \pm 7.5$ & $66.50 \pm 6.9$ & $67.8 \pm 8.1$ & 0.567 \\
\hline Male gender $[n(\%)]$ & $36(82)$ & $17(77)$ & $19(86)$ & 0.696 \\
\hline Current smoker [ $n(\%)]$ & $16(36)$ & $9(41)$ & $7(32)$ & 0.530 \\
\hline Diabetes mellitus [ $n(\%)]$ & $15(34)$ & $6(27)$ & $9(41)$ & 0.526 \\
\hline Hypertension $[n(\%)]$ & $19(43)$ & $8(36)$ & $11(50)$ & 0.361 \\
\hline \multicolumn{5}{|l|}{ NYHA class $[n(\%)]$} \\
\hline I & $1(2)$ & $1(4)$ & $0(0)$ & 0.311 \\
\hline II & $36(82)$ & $17(77)$ & $19(86)$ & 0.434 \\
\hline III & $4(9)$ & $1(4)$ & $3(13)$ & 0.294 \\
\hline \multicolumn{5}{|l|}{ Additional drugs, $n(\%)$} \\
\hline$\beta$-blockers & $15(34.1)$ & 7 (31.8) & $8(36.4)$ & 0.750 \\
\hline $\mathrm{Ca}^{2+}$ channel blockers & $13(30.1)$ & $5(22.7)$ & $8(36.4)$ & 0.321 \\
\hline Nitrates & $29(65.9)$ & $12(54.5)$ & 17 (77.3) & 0.551 \\
\hline Ejection fraction (\%) & $61.9 \pm 10.7$ & $63.22 \pm 10.8$ & $60.59 \pm 10.8$ & 0.872 \\
\hline Creatinine (mg/dl) & $0.9 \pm 0.6$ & $1.07 \pm 0.7$ & $0.88 \pm 0.5$ & 0.328 \\
\hline Total CPB time, min & $101.3 \pm 24.3$ & $100.5 \pm 25.9$ & $102.1 \pm 23.2$ & 0.277 \\
\hline Aortic cross-clamp, min & $65.6 \pm 17.8$ & $63.3 \pm 19.6$ & $68.0 \pm 15.9$ & 0.391 \\
\hline Number of grafts & $3.18 \pm 0.76$ & $3.23 \pm 0.75$ & $3.14 \pm 0.77$ & 0.695 \\
\hline Fluid in the operating room, $\mathrm{ml}$ & $2451.1 \pm 468.0$ & $2577.3 \pm 434.2$ & $2325.0 \pm 476.0$ & 0.073 \\
\hline $\mathrm{PaO}_{2} / \mathrm{FlO}_{2}$ base & $320.7 \pm 115.6$ & $322.5 \pm 134.3$ & $318.9 \pm 96.6$ & 0.919 \\
\hline $\mathrm{PaO}_{2} / \mathrm{FlO}_{2}$ before-CPB & $331.4 \pm 92.8$ & $366.3 \pm 68.6$ & $296.5 \pm 101.8$ & $0.011^{*}$ \\
\hline $\mathrm{PaO}_{2} / \mathrm{FlO}_{2}$ end-CPB & $298.3 \pm 140.0$ & $283.2 \pm 136.2$ & $313.5 \pm 145.4$ & 0.480 \\
\hline
\end{tabular}

Values are expressed as numbers $(n)$, percentages (\%), and means \pm SD.

*Probability value of $P<0.05$ was considered to be significant.

RL, Ringer's lactate; GEL, gelatin; NYHA, New York Heart Association; CPB, cardiopulmonary bypass; Base, before the operation; Before-CPB, before the cardiopulmonary bypass; End-CPB, at the end of cardiopulmonary bypass.

patients were cooled to moderate hypothermia (mean $32{ }^{\circ} \mathrm{C}$ nasopharyngeal temperature). After aortic cross-clamping, all patients received crystalloid cardioplegia for myocardial protection $(800-1000 \mathrm{ml}$, potassium $16 \mathrm{ml} / \mathrm{l}, 4{ }^{\circ} \mathrm{C}$ ). Acid-base balance was managed following the $\alpha$-stat concept. Patients were weaned from $\mathrm{CPB}$ using inotropic support if necessary. After termination of $\mathrm{CPB}$, heparin was neutralized using an equivalent dose of protamine sulphate $3 \mathrm{mg} / \mathrm{kg}$ guided by low filling pressures of $0.9 \% \mathrm{NaCl}$ and gelatin was additionally infused.

At the end of surgery, patients were transferred to the intensive care unit (ICU), where they were treated according to a standard regimen. Haemodynamic values were assessed at a heart rate (HR) of $70-80 \mathrm{beat} / \mathrm{min}$ and a MAP of $65-80 \mathrm{mmHg}$. Inotropic support depended on the individual status of the patient. Basic i.v. fluid administration consisted of $0.9 \% \mathrm{NaCl}$ and gelatin was infused. Fluid balance, rectal temperature, and peripheral temperature (measured on the back of the foot) were recorded every hour. The peripheral circulation $(\Delta T)$ was considered to be adequate if the difference between rectal temperature and peripheral skin temperature was $<5{ }^{\circ} \mathrm{C}$. The lungs were ventilated with $60 \%$ oxygen using volume-controlled ventilation (Servo Ventilator 900C; Siemens,
Stockholm, Sweden) and a tidal volume of $10 \mathrm{ml} /$ $\mathrm{kg}$ with $5 \mathrm{cmH}_{2} \mathrm{O}$ of positive end-expiratory pressure. Analysis of arterial blood gas was conducted by standard techniques using an automated analyser and anaesthesia induction at 4-h intervals for $24 \mathrm{~h}$ after termination of CPB. All patients were extubated in the ICU when the Tobin index [respiratory rate (spontaneous)/tidal volume (L)] was $<105,9,10 \mathrm{PaO}_{2}$ was $>60 \mathrm{mmHg}, \mathrm{FIO}_{2}$ was $<0.4$, continuous positive airway pressure was $<5 \mathrm{mbr}$, $\mathrm{PaCO}_{2}$ was $50 \mathrm{mmHg}$, and arterial $\mathrm{pH}$ was $>7.35$. $\mathrm{PaO}_{2} / \mathrm{FIO}_{2}$.

\section{Intra-operative data}

Intra-operative variables, including $\mathrm{CPB}$ time, aortic cross-clamp time, the need for inotropic support, volume administered during $\mathrm{CPB}$, lowest rectal temperature, urinary output, and the number of aortocoronary bypass grafts, were analysed and recorded (Tables 1 and 2).

\section{Haemodynamic measurements}

$\mathrm{MAP}, \mathrm{HR}$, and central venous pressure (CVP) were measured as haemodynamic indicators. Haemodynamic evaluations were performed before the 


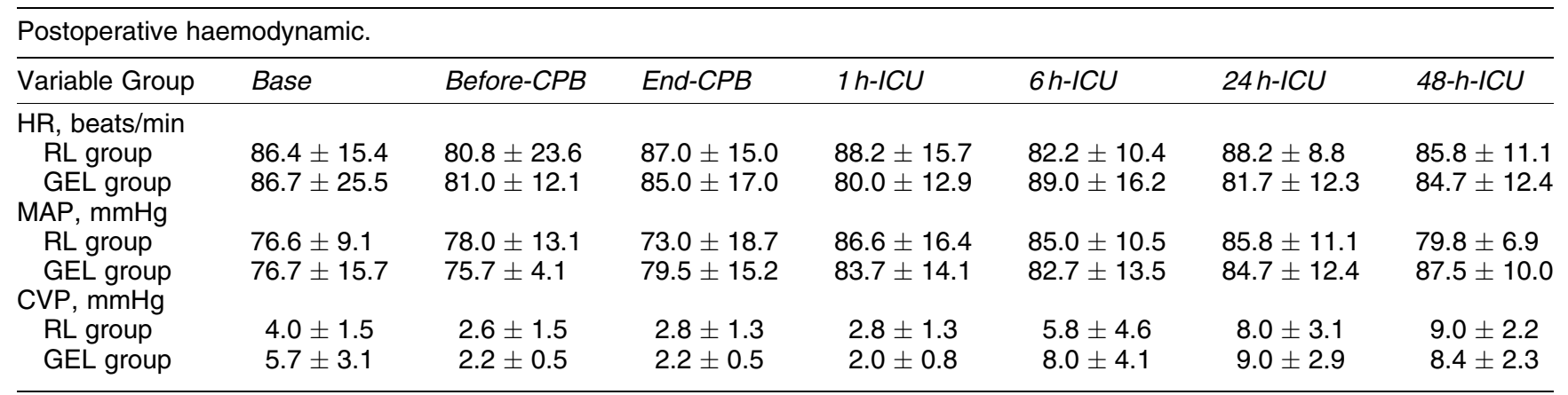

Values are expressed as mean $\pm \mathrm{SD}$.

Base, before the operation; Before-CPB, before the cardiopulmonary bypass; End-CPB, at the end of cardiopulmonary bypass; $1 \mathrm{hr}$ $I C U$, at arrival in the intensive care unit; $6 \mathrm{~h}-I C U, 6 \mathrm{~h}$ after surgery; $24 \mathrm{~h}-I C U, 24 \mathrm{~h}$ after surgery; $48 \mathrm{~h}$-ICU, $48 \mathrm{~h}$ after surgery; $\mathrm{HR}$, heart rate; MAP, mean arterial pressure; CVP, central venous pressure; RL, Ringer's lactate prime; GEL, gelatin prime.

operation (base), before the CPB (before-CPB), at the end of the CPB (end-CPB), on arrival in the ICU ( $1 \mathrm{~h}$ $I C U)$, and at $6 \mathrm{~h}(6 \mathrm{~h}-\mathrm{ICU}), 24 \mathrm{~h}(24 \mathrm{~h}-\mathrm{ICU})$, and $48 \mathrm{~h}$ $(48 \mathrm{~h}-\mathrm{ICU})$ after surgery.

\section{Blood sample collection, stocking, and analysis}

Blood specimens for haemoglobin, haematocrit, white blood cell numbers, platelet counts, and creatinine were collected in 5-ml glass Vacutainer tubes containing EDTA (Becton Dickinson, Norcross, GA). Blood samples for measuring the complement (C4), CRP, and cytokine serum levels were collected via a radial arterial catheter at the following points: before the operation (base), before the $\mathrm{CPB}$ (before- $C P B$ ), at the end of the CPB (end-CPB), on arrival in the ICU ( $1 \mathrm{~h}-\mathrm{ICU})$, and at $6 \mathrm{~h}(6 \mathrm{~h}-\mathrm{ICU})$, $24 \mathrm{~h}(24 \mathrm{~h}-\mathrm{ICU})$, and $48 \mathrm{~h}(48 \mathrm{~h}-\mathrm{ICU})$ after surgery. All blood samples were drawn in pre-chilled vacuum tubes containing EDTA. The samples were immediately centrifuged at $4{ }^{\circ} \mathrm{C}$ and stored at $-80{ }^{\circ} \mathrm{C}$ until assayed. IL-6, IL-8, and TNF- $\alpha$ were determined by ELISA as previously described. ${ }^{11}$ ILs were measured with an ELISA Kit (ELISA; immulite 2000 for IL-6, inmunolite 1000 for IL-8, and inmunolite 1000 for TNF- $\alpha$ DPG, Los Angeles, CA). All assays were controlled according to the manufacturer's instructions. All samples were measured in duplicate. Concentrations were not corrected for dilution. The arterial blood samples for analysing gasometry, haemoglobin, haematocrit, white blood cell numbers, platelet counts, and creatinine and albumin were collected simultaneously. Total C4, CRP, and albumin concentrations were determined by nephelometry (Behring Diagnostics Benelux NV; Behring Nephelometer Analyser, Behringwerke AG, Marburg, Germany), according to the manufacturer's protocol.
Respiratory insufficiency ${ }^{12}$ was indicated by the presence of arterial hypoxemia, defined as a $\mathrm{PaO}_{2} /$ $\mathrm{FIO}_{2}$ ratio $<300$, in any of the determinations.

Blood specimens were obtained for the analysis of cardiac enzymes. Total serum activity of creatinine kinase (CK) was determined by the enzymatic method, and the activity of MB isoenzyme creatine kinase (CK-MB) was quantified by the immunoassay method. CK and CK-MB were evaluated at the following intervals: on arrival in the ICU $(1 \mathrm{~h}$ $I C U)$, and at $6 \mathrm{~h}(6 \mathrm{~h}-I C U), 24 \mathrm{~h}(24 \mathrm{~h}-\mathrm{ICU})$, and $48 \mathrm{~h}$ (48h-ICU) after surgery.

Information regarding clinical, demographic, treatment, and procedural factors, as well as hospital outcome, was obtained prospectively using a specialized case report form.

\section{Statistical analysis}

Before the study, the number of patients required in each group was determined by a power calculation according to data obtained from previous studies on the release of IL- 6 in the patients undergoing cardiac surgery with CPB. ${ }^{6,8,13}$ We hypothesized that purging with gelatin as compared with a RL therapy regimen would reduce the IL-6 response by $30 \%$. A population of 40 patients (20 in each group) would be needed to detect this difference with an $\alpha$ of 0.05 and a power of 0.80 .

Data are presented as mean $( \pm \mathrm{SD})$. Values of IL-6, IL-8, TNF- $\alpha$, CRP, and complement (C4) are represented as medians with interquartile range unless otherwise stated. The SPSS program (version 13) was used for statistical analysis of the data. Raw data were analysed for normality of distribution. If not normally distributed, data were subjected to $\log$ transformation before analysis. We used Fisher's exact test to compare categorical 


\section{E. Tamayo et al.}

variables and Student's $t$-tests to compare continuous variables as appropriate. Differences from baseline and between the groups were evaluated by two-way analysis of variance for repeated measurements (ANOVA), followed by Scheffe's test. Correlation analysis between variables was calculated using Pearson's correlation coefficient. A probability value of $P<0.05$ was considered significant.

\section{Results}

\section{Patients}

Clinical and operative characteristics are shown in Table 1. There were no significant differences between the groups regarding pre-operative data. Patients were similar with regard to type of procedure, bypass time, aortic cross-clamp time, and number of grafts. The $\mathrm{PaO}_{2} / \mathrm{FIO}_{2}$ ratio before $\mathrm{CPB}$ was less in the GEL group than in the RL group $(P=0.011)$. No complications occurred and all patients survived.

\section{Haemodynamic function measurement}

Repeated-measures ANOVA revealed that differences were not significant $(P>0.05)$ over time within groups or between groups for HR, MAP, and CVP measurements (Table 2).

\section{Pre- and postoperative laboratory data}

There were no significant inter-group differences in the haemoglobin, haematocrit, platelet, leukocyte, and albumin counts. The number of leukocytes in both groups increased significantly on arrival in the ICU $\quad(P<0.0001)$. Haemoglobin (before-CPB, $P<0.0001$ ), haematocrit (before- $C P B, P<0.0001$ ), platelet (before-CPB, $P<0.0001$ ), and albumin (before- $C P B, P<0.0001$ ) counts were significantly reduced in both groups as compared with the baseline (Table 3 ).

\section{The postoperative course}

The postoperative course in the two groups showed no significant difference in death, creatinine, respiratory insufficiency, $\mathrm{PaO}_{2} / \mathrm{FIO}_{2}$ ratio, postoperative bleeding, extubation time, number of patients extubated at $24 \mathrm{~h}$, atrial fibrillation, CPK and CPK-MB levels in blood, need for blood transfusion, units of donor blood, need for inotropic support, or length of ICU stay (Table 4). Neither were there any differences between the groups

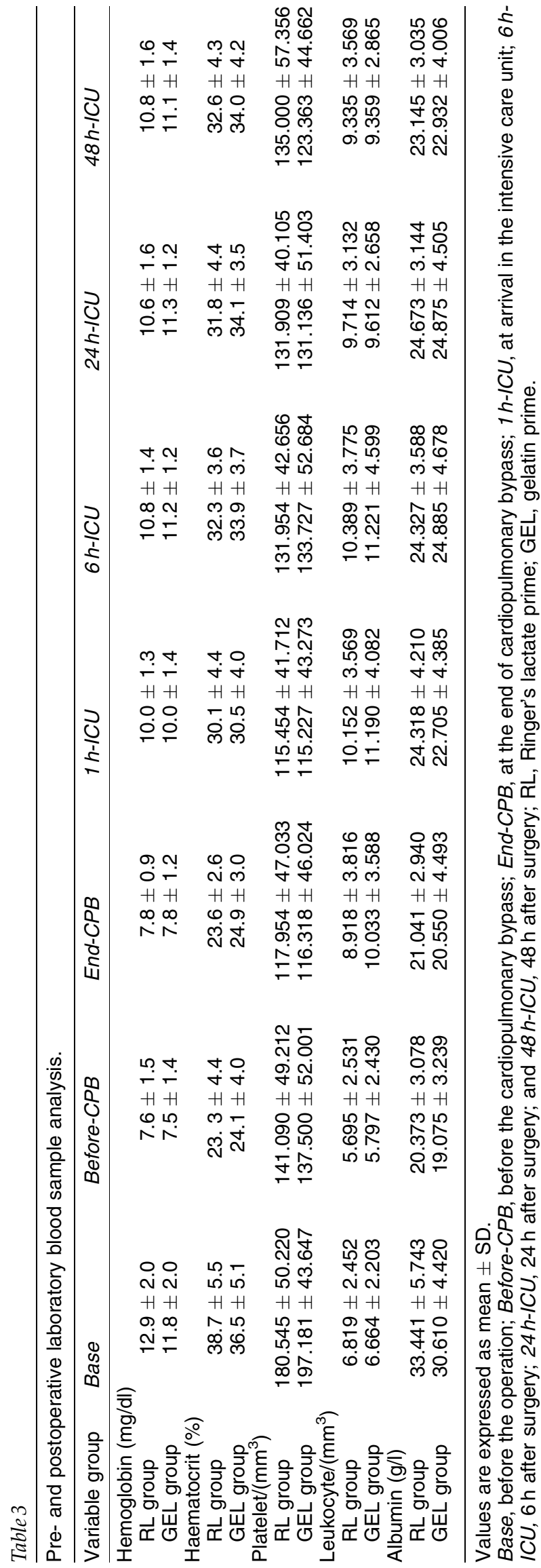




\begin{tabular}{|c|c|c|c|c|}
\hline \multicolumn{5}{|l|}{ Postoperative course } \\
\hline Variable & Total $(n=44)$ & $\mathrm{RL}(n=22)$ & GEL $(n=22)$ & $P$ value \\
\hline Death & 0 & 0 & 0 & $\mathrm{~N} / \mathrm{A}$ \\
\hline Respiratory insufficiency, [n (\%)] & $38(86.4)$ & $17(77.3)$ & $21(95.5)$ & 0.093 \\
\hline $\mathrm{PaO}_{2} / \mathrm{FlO}_{2} 1 \mathrm{~h}-\mathrm{ICU}$ & $269.8 \pm 82.2$ & $273.8 \pm 97.1$ & $265.7 \pm 66.1$ & 0.749 \\
\hline $\mathrm{PaO}_{2} / \mathrm{FlO}_{2} 6 \mathrm{~h}-\mathrm{ICU}$ & $265.0 \pm 89.6$ & $254.7 \pm 72.3$ & $275.2 \pm 104.8$ & 0.456 \\
\hline $\mathrm{PaO}_{2} / \mathrm{FlO}_{2} 24 \mathrm{~h}-\mathrm{ICU}$ & $305.0 \pm 90.3$ & $287.6 \pm 86.8$ & $321.7 \pm 92.4$ & 0.219 \\
\hline Postoperative bleeding (ml/24 h) & $971.8 \pm 510.9$ & $946.0 \pm 537.9$ & $995.0 \pm 496.6$ & 0.760 \\
\hline Time to extubation (hrs) & $12.8 \pm 17.7$ & $11.9 \pm 19.4$ & $13.7 \pm 16.2$ & 0.829 \\
\hline Patients extubated at $24 \mathrm{~h}[n(\%)]$ & $42(95.5)$ & $21(95.5)$ & $21(95.5)$ & 0.742 \\
\hline Atrial fibrillation & 1 & 0 & 1 & N/A \\
\hline CK (IU/I) & $705.03 \pm 672.73$ & $582.0 \pm 332.42$ & $816.33 \pm 869.28$ & 0.262 \\
\hline CK-MB (IU/I) & $94.33 \pm 176.31$ & $53.74 \pm 40.3$ & $131.05 \pm 237.01$ & 0.156 \\
\hline Need for blood transfusion $[n(\%)]$ & $33(75 \%)$ & $17(89.5 \%)$ & $16(94.1 \%)$ & 0.412 \\
\hline Need for inotropic support [n (\%)] & $20(45.5)$ & $8(36.4)$ & $12(54.5)$ & 0.225 \\
\hline Mean ICU stay (days) & $2.3 \pm 2.0$ & $2.10 \pm 1.8$ & $2.64 \pm 2.2$ & 0.388 \\
\hline
\end{tabular}

Values are expressed as numbers $(n)$, percentages $(\%)$, and mean \pm SD.

*Probability value of $P<0.05$ was considered to be significant.

$\mathrm{RL}$, Ringer's lactate prime; GEL, gelatin prime; CK, creatinine kinase; CK-MB, MB isoenzyme creatine kinase; ICU, intensive care unit.

with regard to the total volume of fluid administered during the intra-operative (Table 1) and postoperative period (Table 4). The $\mathrm{PaO}_{2} / \mathrm{FIO}_{2}$ ratio in the colloid group was significantly lower $(P=0.032)$ as compared with the crystalloid group $48 \mathrm{~h}$ after arrival in the ICU. One patient in the RL group had prolonged ventilation, while one of the 44 total patients had atrial fibrillation with fast ventricular rate $(120-180 \mathrm{bpm})$, requiring antiarrhythmic therapy.

\section{Levels of plasma cytokines}

Repeated-measures ANOVA revealed that, within each group, variations in the plasma levels of IL-6, IL-8, and TNF- $\alpha$ compared with baseline values were significant over time. Compared with the initial levels (base), IL-6 levels peaked at $6 \mathrm{~h}$ after surgery $(P<0.0001)$, showing a continuous decrease in the first $48 \mathrm{~h}$ after surgery (Fig. 1A). IL-8 levels underwent a similar trend in both groups, peaking at $1 \mathrm{~h}$ after arrival in the ICU $(P<0.0001)$ and a progressive return towards the baseline value $48 \mathrm{~h}$ after surgery (Fig. 1B). TNF- $\alpha$ levels increased progressively in both groups to reach a peak at $4 \mathrm{~h}$ after surgery in the RL group $(P<0.0001)$ and $6 \mathrm{~h}$ after surgery in the GEL group $(P<0.0001)$, with a slight return towards baseline values at $48 \mathrm{~h}$ after surgery (Fig. 1C). However, when analysed by repeated-measures ANOVA, no significant difference was found between the groups in IL-6, IL-8, and TNF- $\alpha$ plasma levels at any time point.

Furthermore, no significant correlation was found between cytokine plasma levels (IL-6, IL-8, and $\mathrm{TNF}-\alpha$ ) and clinical postoperative variables such as respiratory insufficiency, $\mathrm{PaO}_{2} / \mathrm{FIO}_{2}$ ratio, extubation time, CK, CK-MB, need for inotropic support, and length of stay in ICU in either group.

\section{Plasma levels of CRP and complement (C4)}

CRP levels increased in all patients, starting from $6 \mathrm{~h}$ in ICU and reaching maximum levels at $48 \mathrm{~h}$ inICU $(P<0.0001)$ (Fig. 2A). C4 levels decreased significantly $(P<0.0001)$ during the first minutes of $\mathrm{CPB}$, mainly because of haemodilution (Fig. 2B). Thereafter, levels slightly increased, returning to base values at $48 \mathrm{~h}-\mathrm{ICU}(P=0.425)$. Repeated measures of variance analysis (ANOVA) revealed these differences were significant over time within groups in the plasma level of CRP and C4, but no significant differences were found between groups at any sample point.

\section{Discussion}

This prospective, randomized study was designed to examine any potential effect of priming the extracorporeal circuit with crystalloid (RL) rather 

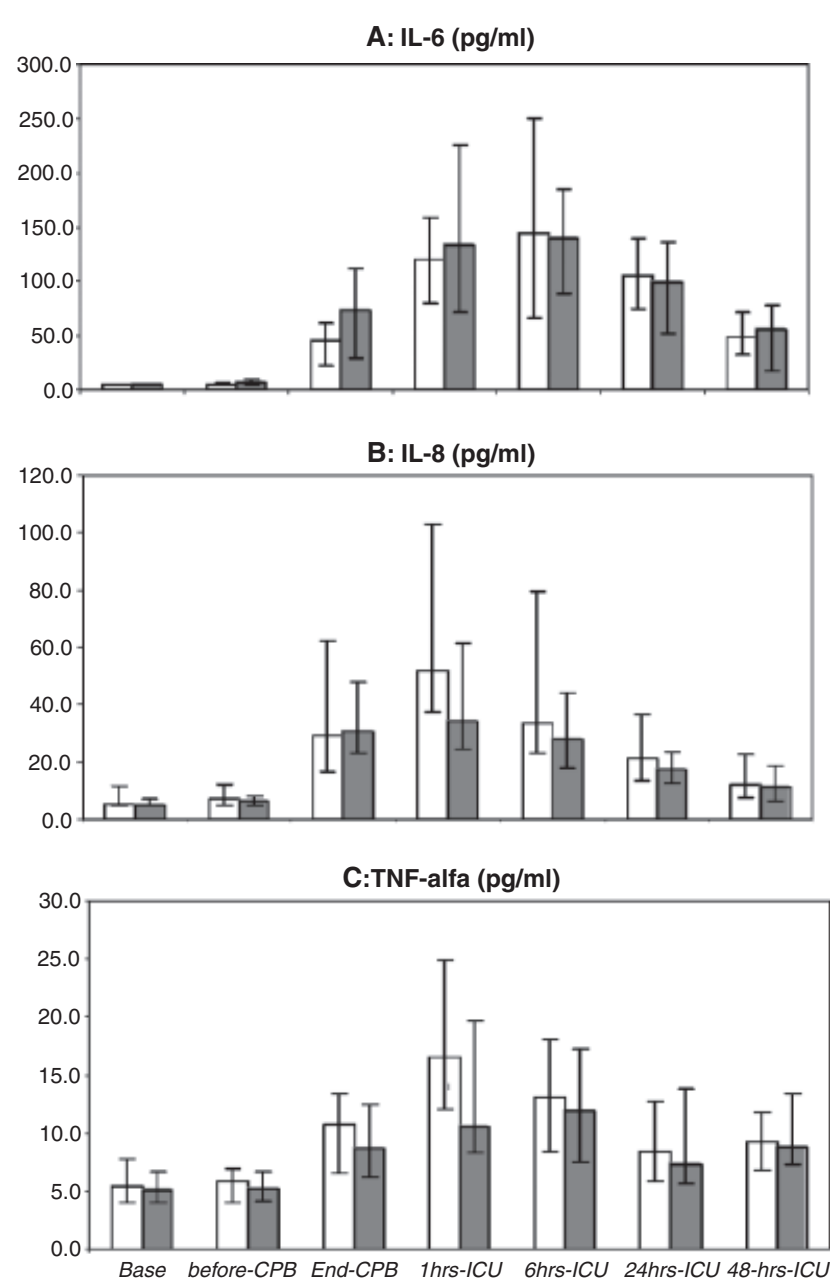

Fig. 1. Temporal profile of cytokines. Median plasma levels of $(A)$ interleukin IL-6, (B) IL-8, and (C) tumor necrosis factor (TNF- $\alpha$ ) in patients treated with Ringer's lactate (RL) prime (light bars) or gelatin (GEL) prime (dark bars) at different sampling times. Base, before the operation; Before-CPB, before the cardiopulmonary bypass; End-CPB, at the end of cardiopulmonary bypass; $1 \mathrm{~h}-$ ICU, at arrival in the intensive care unit; $6 \mathrm{~h}-\mathrm{ICU}, 6 \mathrm{~h}$ after surgery; $24 \mathrm{~h}-\mathrm{ICU}, 24 \mathrm{~h}$ after surgery; and $48 \mathrm{~h}-\mathrm{ICU}, 48 \mathrm{~h}$ after surgery. Data represent the median and interquartile range.

than colloid (gelatin) on post-surgical inflammatory response. The two groups analysed were homogeneous as far as demographic and clinical data are concerned, and the sample size was sufficient for comparing the two groups. We did not detect any differences in the inflammatory response (serum levels of the pro-inflammatory cytokines IL-6, IL-8, and TNF- $\alpha$; levels of C4, CRP, and leukocytes) or any relevant adverse effects (such as arrhythmia, respiratory insufficiency, etc.) during or after the bypass cardiopulmonary procedure (up to $48 \mathrm{~h}$ post procedure).
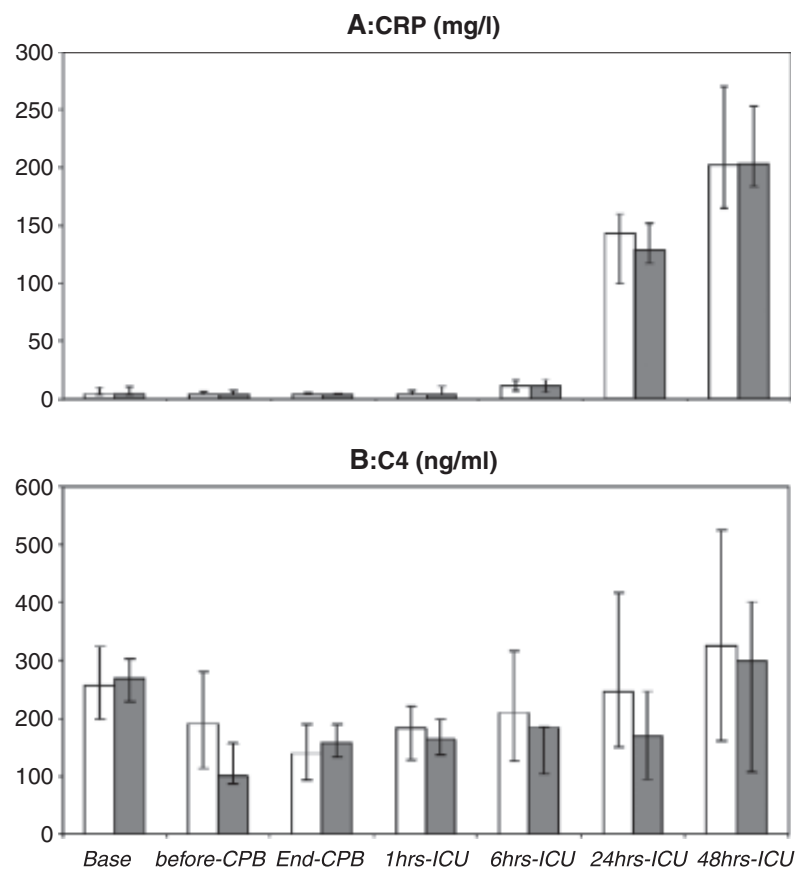

Fig. 2. Temporal profile of $C$-reactive protein $(A)$ and complement (B). Median plasma levels in patients treated with Ringer's lactate (RL) prime (light bars) or gelatin (GEL) prime (dark bars) at different sampling times. Base, before the operation; Before-CPB, before the cardiopulmonary bypass; End-CPB, at the end of cardiopulmonary bypass; $1 \mathrm{~h}-\mathrm{ICU}$, at arrival in the intensive care unit; $6 \mathrm{~h}$-ICU, 6 h after surgery; $24 \mathrm{~h}-\mathrm{ICU}, 24 \mathrm{~h}$ after surgery; and $48 \mathrm{~h}-\mathrm{ICU}, 48 \mathrm{~h}$ after surgery. Data represent the median and interquartile range.

The onset of CPB was associated with an intense SIRS, characterized by the activation of complement, neutrophils, endotoxin, elastases, and the pro-inflammatory cytokines. ${ }^{14-16}$ The present study confirms $^{3,6,8,14}$ that on altering the CPB, there is an intense SIRS accompanied by high levels of the common pro-inflammatory cytokines (TNF- $\alpha$, IL-6, and IL-8), CRP, C4, and leukocytes.

Colloid-containing priming solutions are advocated to prevent the initial decrease in colloid osmotic pressure at the beginning of $\mathrm{CPB},{ }^{8,17}$ and the clinical benefits of a normal colloid osmotic pressure include reduced fluid administration, improved postoperative patient recovery, and a shortened postoperative hospital stay. ${ }^{\circ}$ In further support of colloid solution use in CPB purging, neutrophil and complement activation have been shown to be reduced with colloid use, ${ }^{4-7}$ as well as a reduction in plasma water, thus lowering the inflammatory response.

According to the results of this study, however, this hypothesis has not been confirmed, as the 
pattern of changes in the blood levels of cytokines, CRP, and complement was similar in both the group that used GEL and the group that used RL for priming the CPB. A previous study that evaluated the efficacy of $\mathrm{CPB}$, using either GEL priming $(1650 \mathrm{ml})$ or RL priming $(1650 \mathrm{ml})$, showed that maintaining a normal colloid osmotic pressure during $\mathrm{CPB}$ can be established by adding GEL to the priming solution of an extracorporeal circuit with a small prime volume. ${ }^{8}$ Similar increments in TNF- $\alpha$, complement, and neutrophil elastase were found in both groups as indicators of SIRS.

In this study we have evaluated gelatin, a colloid used in our centre for priming the CPB. Gelatin is derived from bovine collagen, and the animal peptide nature of gelatin may confer an enhanced immunogenicity compared with other solution fluids (hydroxyethyl starch, Ringer's solution). Recent studies demonstrate that the use of gelatin solutions as volume replacement regimens in both animals $^{18}$ and the elderly undergoing major abdominal surgery is associated with a significant and marked increase in IL- 6 and TNF- $\alpha$ as compared with the use of Ringer's or $4 \%$ hydroxyethyl starch solutions. ${ }^{19,20}$ In our study, the lack of any observed differences in the levels of cytokines, CRP, and complement between colloid and crystalloid priming of the $\mathrm{CPB}$ may be due to the greater intensity of the surgical trauma and/or CPB's liberation of cytokines during cardiac surgery, ${ }^{21}$ so that the effect of the purging liquids, whether colloid or crystalloid, is minimized and masked by these other factors.

Recent studies demonstrate that maintenance of cardiovascular stability and effective organ perfusion with fluid solutions is associated with an attenuation of the inflammatory response. ${ }^{22,23} \mathrm{Be}-$ cause of relatively slow degradation of the gelatinbased colloid, the volume expanding effect is maintained for 2-3 h, while the volume expanding effect of crystalloids (Ringer) is markedly shorter. Gelatin-based colloid has been considered to be effective in improving haemodynamics, the peripheral perfusion, and the optimization of the patient's intravascular volume status. ${ }^{18}$ Consequently, one could suppose that differences in inflammatory response are related to the degree of intravascular volume (which depends on the type of plasma expander used). Nevertheless, no differences were observed between the two groups in our study. To avoid any distortion of the results, one of the aims was to maintain a MAP (65$80 \mathrm{mmHg}$ ) throughout the entire period of study in both groups. The absence of significant changes in pro-inflammatory cytokines and CRP between the two groups of patients was also reinforced by the absence of significant modifications in haemodynamic and peri-operative variables. Three clinically available parameters (blood pressure, haematocrit, and CVP) were also used to test the effectiveness of volume expansion with different fluids. The results generally demonstrated equal efficacy for both fluids on adequate perfusion. Haematocrit, haemoglobin, and albumin decreased after beginning $\mathrm{CPB}$ as a consequence of the effect of haemodilution with clear priming solutions.

From a clinical point of view, CPB has been associated with a large variety of clinical symptoms, ${ }^{1}$ and the extent of their intensity has been correlated with the levels of cytokines and complement, and the severity of the SIRS. ${ }^{2-4}$ However, we were not able to find a significant correlation between plasma levels (IL-6, IL-8, and TNF- $\alpha$ ) and peri-operative variables. As for the presence of relevant adverse effects related with postpump syndromes (respiratory insufficiency, levels of CPK-MB, need for inotropic support, units of donor blood, need for blood transfusion etc.), there were no differences between the two groups. Chello et al. ${ }^{24}$ did not find any correlation between the levels of cytokines and the adverse effects.

The conclusions from these results, however, may be limited because (i) it is probable that the sample size of the present study is not sufficient to assess clinical outcomes such as intubation time, length of stay in ICU, and postoperative pulmonary morbidity, which are low in our patients, and (ii) it is also possible that the sample size is not sufficient to establish any correlation between the levels of cytokines and pre- and postoperative variables. Furthermore, to both groups we have administered aprotinin, which is known to have anti-inflammatory properties. ${ }^{2}$

Our study provides no significant clinical advantages for colloid priming as compared with crystalloid priming: the blood levels of cytokines, CRP, and complement and leucocytes, and the haemodynamic and clinical profiles were similar. Thus, as colloid use increases the costs and does not bring any advantages, we believe that its routine use is not justified in coronary artery bypass grafting.

To conclude, on the basis of our data we can affirm that priming with colloid as opposed to crystalloid in patients undergoing coronary artery bypass grafting with $\mathrm{CPB}$ produces no significant 


\section{E. Tamayo et al.}

differences in the inflammatory response as measured by the levels of IL- 6 , IL- 8 , TNF- $\alpha$, CRP, and $\mathrm{C} 4$. On the basis of these data, we recommend the routine use of crystalloids for priming the CPB.

\section{References}

1. Westaby S. Organ dysfunction after cardiopulmonary bypass: a systemic inflammatory reaction initiated by the extra-corporeal circuit. Intensive Care Med 1987; 13: 89-95.

2. Hill GE, Whitten CW, Landers DF. The influence of cardiopulmonary bypass of cytokine and cell to cell communication. J Cardiothorac Vasc Anesthesia 1997; 11: 367-75.

3. Hennein HA, Ebba H, Rodriguez JL, Merrick SH, Keith FM, Bronstein MH, Leung JM, Mangano DT, Greenfield LJ, Rankin JS. Relationship of the proinflammatory cytokines to myocardial ischemia and dysfunction after uncomplicated coronary revascularization. J Thorac Cardiovasc Surg 1994; 108: 626-35.

4. ElHabbal MH, Smith LJ, Elliot MJ, Strobel S. Cardiopulmonary bypass tubes and prime solutions stimulate neutrophil adhesion molecules. Cardiovasc Res 1997; 33: 209-15.

5. Bonser RS, Dave JR, Davies ET, John L, Taylor P, Gaya H, Lennox SC, Vergani D. Reduction of complement activation during bypass by prime manipulation. Ann Thorac Surg 1990; 49: 279-83.

6. Steinberg JB, Kapelanski DP, Olson JD, Weiler JM. Cytokine and complement levels in patients undergoing cardiopulmonary bypass. J Thorac Cardiovasc Surg 1993; 106: 1008-16.

7. Cavarocchi NC, Pluth JR, Schaff HV, Orszulak TA, Homburger HA, Solis E, Kaye MP, Clancy MS, Kolff J, Deeb GM. Complement activation during cardiopulmonary bypass. Comparison of bubble and membrane oxygenators. J Thorac Cardiovasc Surg 1986; 91: 252-8.

8. Jansen PGM, te Velthuis H, Wildevuur WR, Huybregts MAJM, Bulder ER, van der Spoel HI, Eijsman LH. Cardiopulmonary bypass with modified fluid and heparin-coated circuits cardiopulmonary bypass with heparin-coated circuits. Br J Anaesth 1996; 76: 13-9.

9. Tobin MJ. Advances in mechanical ventilation. $N$ Engl J Med 2001; 344: 1986-96.

10. Bone RC, Balk RA, Cerra FB, Dellinger RP, Fein AM, Knaus WA, Schein RMH, Sibbald WJ. Definitions for sepsis and organ failure and guidelines for the use of innovative therapies in sepsis. The ACCP/SCCM Consensus Conference Committee. American College of Chest Physicians/Society of Critical Care Medicine. Chest 1992; 101: 1644-55.

11. Helle M, Boeije L, de Groot ER, de Vos A, Arden LA. Sensitive ELISA for interleukin 6: detection of IL-6 in biological fluids: synovial fluids and sera. J Imunnol Methods 1991; 138: 47-5.

12. Levy MM, Fink MP, Marshall JC, Abraham E, Angus D, Cook D, Opal SM, Vincent JL, Ramsay G. International Sepsis Definitions Conference. 2001 SCCM/ESICM/
ACCP/ATS/SIS International Sepsis Definitions Conference. Intensive Care Med 2003; 29: 530-8.

13. Cremer J, Martin M, Redl H, Bahrami S, Abraham C, Graeter T, Haverich A, Schlag G, Borst HG. Systemic inflammatory response syndrome after cardiac operations. Ann Thorac Surg 1996; 61: 1714-20.

14. Butler J, Rocker GM, Westaby S. Inflammatory response to cardiopulmonary bypass. Ann Thorac Surg 1993; 55: 552-9.

15. Fong Y, Moldawer LL, Shires GT, Lowry SF. The biologic characteristics of cytokines and their implication in surgical injury. Surg Gynecol Obstet 1990; 170: 363-78.

16. Rangel-Frausto MS, Pittet D, Costigan M, Hwang T, Davis $\mathrm{CH}$, Weszal RP. The natural history of the systemic inflammatory response syndrome (SIRS). JAMA 1995; 273: 117-23.

17. Sánchez de Leon R, Paterson JL, Sykes MK. Changes in colloid osmotic pressure with plasma albumin concentration associated with extracorporeal circulation. $\mathrm{Br}$ J Anaesthesia 1982; 54: 465-74.

18. Lee CC, Chang IJ, Yen ZS, Hsu CY, Chen SY, Su CP, Chiang WC, Chen SC, Chen WJ. Effect of different resuscitation fluids on cytokine response in a rat model of hemorrhagic shock. Shock 2005; 24: 177-81.

19. Boldt J, Ducke M, Kumle B, Papsdorf M, Zurmeyer EL. Influence of different volume replacement strategies on inflammation and endothelial activation in the elderly undergoing major abdominal surgery. Intensive Care Med 2004; 30: 416-22.

20. Lang K, Suttner S, Boldt J, Kumle B, Nagel D. Volume replacement with HES 130/0.4 may reduce the inflammatory response in patients undergoing major abdominal surgery. Can J Anaesth 2003; 50: 1009-16.

21. Prondzinsky R, Knupfer A, Loppnow H, Redling F, Lehmann DW, Stabenow I, Witthaut R, Unverzagt S, Radke J, Zerkowski HR, Werdan K. Surgical trauma affects the proinflammatory status after cardiac surgery to a higher degree than cardiopulmonary bypass. J Thorac Cardiovasc Surg 2005; 129: 760-6.

22. Engel JM, Welters I, Rupp M, Langefeld T, Ruwoldt R, Menges T, Hempelmann G. Influence of colloid fluids on polymorphonuclear granulocyte function in vivo. Acta Anaesthesiol Scand 2001; 45: 385-9.

23. Jaeger K, Heine J, Ruschulte H, Juttner B, Scheinichen D, Kuse ER, Piepenbrock S. Effects of colloidal resuscitation fluids on the neutrophil respiratory burst. Transfusion 2001; 41: 1064-8.

24. Chello M, Patti G, Candura D, Mastrobuoni S, Di Sciascio G, Felice F, Carassiti M, Covino E. Effects of atorvastatin on systemic inflammatory response after coronary bypass surgery. Crit Care Med 2006; 34: 660-7.

Address:

Eduardo Tamayo

Department of Anaesthesiology and Reanimation

Valladolid University Hospital

Valladolid

Spain

e-mail: tamayo@med.uva.es 